\title{
QUEEN'S
UNIVERSITY
BELFAST
}

\section{Dynamically Reconfigurable SIR Filter Using Rectenna and Active Booster}

Quddious, A., Abbasi, M. A. B., Saghir, A., Arain, S., Antoniades, M. A., Polycarpou, A., Vryonides, P., \&

Nikolaou, S. (2019). Dynamically Reconfigurable SIR Filter Using Rectenna and Active Booster. IEEE

Transactions on Microwave Theory and Techniques, 67(4), 1504. https://doi.org/10.1109/TMTT.2019.2891524

Published in:

IEEE Transactions on Microwave Theory and Techniques

Document Version:

Peer reviewed version

Queen's University Belfast - Research Portal:

Link to publication record in Queen's University Belfast Research Portal

Publisher rights

(c) 2019 IEEE.

\section{General rights}

Copyright for the publications made accessible via the Queen's University Belfast Research Portal is retained by the author(s) and / or other copyright owners and it is a condition of accessing these publications that users recognise and abide by the legal requirements associated with these rights.

Take down policy

The Research Portal is Queen's institutional repository that provides access to Queen's research output. Every effort has been made to ensure that content in the Research Portal does not infringe any person's rights, or applicable UK laws. If you discover content in the Research Portal that you believe breaches copyright or violates any law, please contact openaccess@qub.ac.uk. 


\title{
Dynamically Reconfigurable SIR Filter using Rectenna and Active Booster
}

\author{
Abdul Quddious, Student Member, IEEE, Muhammad Ali Babar Abbasi, Member, IEEE, Aqeela \\ Saghir, Salman Arain, Student Member, IEEE, Marco A. Antoniades, Senior Member, IEEE, Alexis \\ Polycarpou, Member, IEEE, Photos Vryonides, Member, IEEE and Symeon Nikolaou, Member, IEEE
}

\begin{abstract}
A novel dynamically reconfigurable bandpass filter (BPF) employing stepped impedance resonators (SIRs) that can operate as either a single-band or a dual-band filter is demonstrated. The reconfigurable BPF uses four $p$-i-n diodes as switching elements. With the four p-i-n diodes in the "OFF" state, the filter behaves as a low-loss $(0.85 \mathrm{~dB})$ single-band BPF with a passband around $2.45 \mathrm{GHz}$. The reconfigurable SIR filter can operate as a dual-band bandpass filter with two center frequencies at $1.6 \mathrm{GHz}$ and $2.45 \mathrm{GHz}$. The diodes are dynamically set to the "ON" state in the presence of a 1.6 GHz RF signal that is received by an RF triggered power management unit (PMU), integrated on the back side of the microstrip filter in a dual-layer architecture. The RF triggered PMU consists of a PIFA antenna, a highefficiency voltage doubler rectifier $(47 \%$ at $-13 \mathrm{dBm})$ and an active dc-to-dc power booster. The rectified output voltage is used as the enabling voltage for the dc-to-dc power booster. This, in turn, provides the required dc power for the diodes biasing. The filter switches from single-band to dual-band when a wireless input RF signal (>-13 dBm) is received by the RF triggered PMU's antenna.
\end{abstract}

Index Terms - Microwave filter, reconfigurable, rectenna wireless power transfer.

\section{INTRODUCTION}

$\mathrm{T}$ HERE has been an increasing demand for switchable and reconfigurable microwave devices, such as filters for wireless communication systems, where several different wireless devices co-exist and share the same frequency spectrum. Band pass filters (BPFs) with multi-frequency response and high stopband rejection are widely used, therefore reconfigurable BPFs can be utilized for controlling either standalone signals or combinations of information signals, with different frequency spectrum characteristics [1], [2]. In [1] a

This work was supported in part by the European Union through the Erasmus Mundus INTACT Doctorate Level Mobility program.

A. Quddious, A. Saghir, S. Arain, A.Polycarpou are with the Department of Electrical Engineering, Frederick University, 7, Y. Frederickou Str. Pallouriotisa, Nicosia 1036 Cyprus (e-mail: 12mseeaquddious@ seecs.edu.pk).

M. Ali Babar Abbasi is with The Centre for Wireless Innovation (CWI), The Institute of Electronics, Communications and Information Technology (ECIT), School of Electronics, Electrical Engineering and Computer Science (EEECS), Queen's University Belfast, Belfast BT3 9DT, United Kingdom (email: m.abbasi@qub.ac.uk).

M.A Antoniades is with the Electrical and Computer Engineering Department, University of Cyprus, Kallipoleos 75, Nicosia 1678, Cyprus (email: mantonia@ucy.ac.cy).

P. Vryonides and S. Nikolaou are with the Frederick University, and Frederick Research Center (FRC) 7, Y. Frederickou Str. Pallouriotisa, Nicosia 1036 Cyprus (e-mail: s.nikolaou@ frederick.ac.cy).

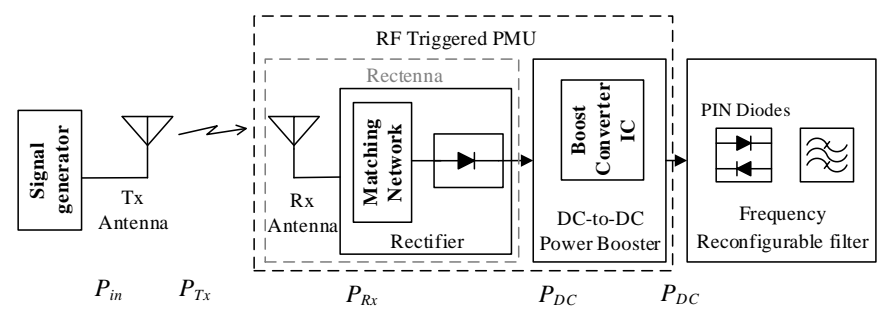

(a)

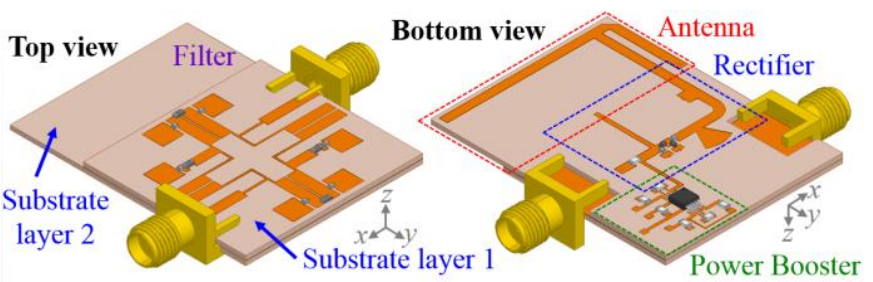

(b)

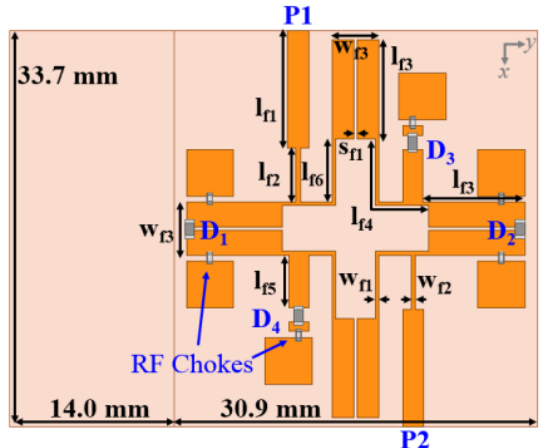

(c)

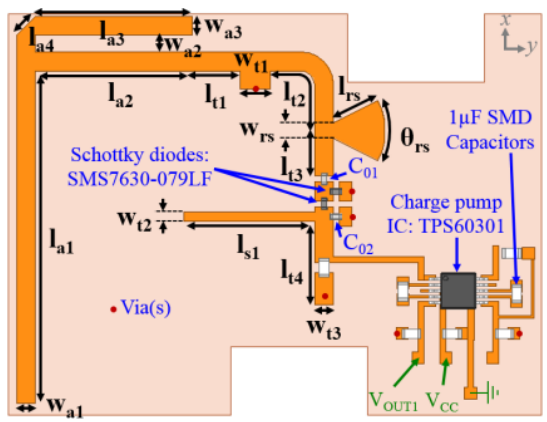

(d)

Fig. 1. (a) Schematic diagram of the dynamically reconfigurable filter, (b) constituent elements of the dual-layer module (c) Layer 1-layout of the reconfigurable single-band to dual-band BPF and (d) Layer 2-RF triggered PMU (antenna + rectifier + dc-to-dc power booster). 
TABLE I

COMPONENT DIMENSIONS FROM FIG. 1

\begin{tabular}{|c|c|c|c|c|}
\hline $\begin{array}{l}\text { Parameter } \\
\text { Value }\left(\mathrm{mm}^{2}\right)\end{array}$ & $\begin{array}{l}\text { Filter } \\
30.90 \times\end{array}$ & .70 & $\begin{array}{l}\mathbf{R F} \text { Tr } \\
44.90\end{array}$ & $\begin{array}{l}\text { red PMU } \\
70\end{array}$ \\
\hline \multicolumn{5}{|c|}{ Filter } \\
\hline $\begin{array}{l}\text { Parameter } \\
\text { Value }(\mathrm{mm})\end{array}$ & $\begin{array}{l}l_{\mathrm{f} 1} \\
10.00\end{array}$ & $\begin{array}{l}1_{\mathrm{f} 2} \\
4.60\end{array}$ & $\begin{array}{l}l_{\mathrm{f} 3} \\
8.30\end{array}$ & $\begin{array}{l}\mathrm{l}_{\mathrm{f} 4} \\
10.20\end{array}$ \\
\hline $\begin{array}{l}\text { Parameter } \\
\text { Value }(\mathrm{mm})\end{array}$ & $\begin{array}{l}1_{\mathrm{f} 5} \\
4.50\end{array}$ & $\begin{array}{l}1_{\mathrm{f} 6} \\
6.50\end{array}$ & $\begin{array}{l}\mathrm{W}_{\mathrm{f} 1} \\
0.30\end{array}$ & $\begin{array}{l}\mathrm{W}_{\mathrm{f} 2} \\
0.40\end{array}$ \\
\hline $\begin{array}{l}\text { Parameter } \\
\text { Value }(\mathrm{mm})\end{array}$ & $\begin{array}{l}\mathrm{W}_{\mathrm{f} 3} \\
4.00\end{array}$ & $\begin{array}{l}\mathrm{s}_{\mathrm{f} 1} \\
0.30\end{array}$ & $\begin{array}{l}\mathrm{S}_{\mathrm{f} 2} \\
0.30\end{array}$ & \\
\hline \multicolumn{5}{|c|}{ Antenna } \\
\hline $\begin{array}{l}\text { Parameter } \\
\text { Value }(\mathrm{mm})\end{array}$ & $\begin{array}{l}l_{\mathrm{a} 1} \\
27.90\end{array}$ & $\begin{array}{l}l_{\mathrm{a} 2} \\
11.70\end{array}$ & $\begin{array}{l}l_{\mathrm{a} 3} \\
13.23\end{array}$ & $\begin{array}{l}l_{\mathrm{a} 4} \\
2.26\end{array}$ \\
\hline $\begin{array}{l}\text { Parameter } \\
\text { Value }(\mathrm{mm})\end{array}$ & $\begin{array}{l}\mathrm{W}_{\mathrm{a} 1} \\
1.60\end{array}$ & $\begin{array}{l}\mathrm{W}_{\mathrm{a} 2} \\
1.60\end{array}$ & $\begin{array}{l}\mathrm{W}_{\mathrm{a} 3} \\
1.40\end{array}$ & \\
\hline \multicolumn{5}{|c|}{ Rectifier } \\
\hline $\begin{array}{l}\text { Parameter } \\
\text { Value (mm) }\end{array}$ & $\begin{array}{l}1_{t 1} \\
5.57\end{array}$ & $\begin{array}{l}l_{\mathrm{t} 2} \\
3.45\end{array}$ & $\begin{array}{l}1_{13} \\
3.20\end{array}$ & $\begin{array}{l}\mathrm{l}_{\mathrm{t}} \\
3.44\end{array}$ \\
\hline $\begin{array}{l}\text { Parameter } \\
\text { Value (mm) }\end{array}$ & $\begin{array}{l}1_{\mathrm{s} 1} \\
11.00\end{array}$ & $\begin{array}{l}1_{\mathrm{rs}} \\
4.17\end{array}$ & $\begin{array}{l}\mathrm{W}_{\mathrm{rs}} \\
1.32\end{array}$ & $\begin{array}{l}\theta_{\mathrm{rs}} \\
65^{\circ}\end{array}$ \\
\hline $\begin{array}{l}\text { Parameter } \\
\text { Value }(\mathrm{mm})\end{array}$ & $\begin{array}{l}\mathrm{W}_{\mathrm{t} 1} \\
1.60\end{array}$ & $\begin{array}{l}\mathrm{W}_{\mathrm{t} 2} \\
0.77\end{array}$ & $\begin{array}{l}\mathrm{W}_{\mathrm{t} 3} \\
2.50\end{array}$ & \\
\hline
\end{tabular}

compact switchable BPF with two-state frequency responses is reported, however the out-of-band filter performance is not presented. In [2] a novel class of bandpass filters where both center frequency and passband bandwidth can be reconfigured electronically is presented but the size of the proposed filters is relatively large. Occasionally, it is necessary for reconfigurable filters to have either dual-band or single-band response. A lot of research has been conducted in this area, and various approaches have been attempted in order to realize dual-band characteristics. Generally, there are two dominant techniques. The first, is to join a number of independent resonators with common input/output ports [3]-[5], and the second is to use stepped impedance resonators (SIRs) [6]-[9]. In [3] a compact dual-band BPF based on parallel short-ended feed scheme is presented but it needs at least four resonators resulting in a large size whereas in [4] ring resonators are employed to obtain the dual band response leading to complicated filter configurations. In [5] a switchable dual-band filter with diodes connected at the resonators was introduced. However, six diodes were implemented resulting in a complex circuit and also the process of designing the central frequencies and the fractional bandwidths is not straightforward. A dual-band BPF using nettype resonators operating at $1 / 2.05 \mathrm{GHz}$ is proposed in [6] and in [7] multistage SIRs are employed in the dual-band BPF to achieve a wide upper rejection band. In [9] a single-band switchable BPF using SIRs and p-i-n diodes was presented with good selectivity and stopband rejection with the disadvantage though of very large circuitry and poor insertion loss. However, the dual-band BPFs realized with these techniques cannot switch to operate in only one passband easily. In this work, a new type of dynamically reconfigurable BPF consisting of stepped impedance resonators with coupled-line sections, able to operate with either a single- or a dual-band characteristic is proposed, as shown in Fig. 1, having the advantage of exhibiting harmonic suppression, low insertion loss and sharp selectivity using the same resonator. To achieve the reconfigurability, Positive-Intrinsic-Negative ( $\mathrm{p}-\mathrm{i}-\mathrm{n})$ diodes are used as switches. Most reconfigurable devices change their configuration as a result of a decision, made externally by the user [10], [11]. The proposed dynamically reconfigurable filter changes its configuration based on the existence or the absence of ambient RF power that is wirelessly received by an RF scavenging unit implemented on the back layer of the dual-layer filter. The filter operates as a single-band BPF at $2.45 \mathrm{GHz}$, and when an ambient RF signal at $1.6 \mathrm{GHz}$ is received it triggers a power management unit (PMU) that supplies the necessary dc power to switch the state of four p-i-n diodes to "ON". With the four diodes in the "ON" state the filter is converted from a single-band filter into a dual-band BPF, with one passband at 1.6 GHz and another passband at $2.45 \mathrm{GHz}$.

Recent technology trends for "smart" wireless systems have enabled the control or even the operation of microwave devices, wirelessly. In most cases, the harvested power is not enough to provide sufficient autonomous operation. However, the received RF signal can be exploited in order to control a power management unit (PMU) to supply the required power. In order to achieve maximum sensitivity, meaning the effective sensing of a low power RF signal, it is desirable to design a high efficiency rectenna (antenna + rectifier) for the entire range of the available power levels. Considerable research has been conducted in the past decade towards high efficiency rectifiers for both low power [12]-[17] and high power [18]-[22] RF energy rectification. Following the rectifier, a power management unit (PMU) is usually employed, in an attempt to provide the optimum termination load for the rectifier, since the efficiency of the RF-to-dc power conversion has a non-linear dependency on the load [12]. Some of the power management units presented in the literature, focus on switching converters to effectively store the harvested energy into a rechargeable battery [23]-[25]. However, for the dynamically reconfigurable filter presented in this work, the rectified RF energy is not stored, but it is instead used as a trigger signal, enabling the PMU to supply the necessary dc power to the $\mathrm{p}-\mathrm{i}-\mathrm{n}$ diodes. Consequently, the PMU is triggered from the rectified RF input signal. The proposed dual-layer device consists of a reconfigurable SIR filter on one layer, and a rectenna operating at $1.6 \mathrm{GHz}$, cascaded with a charge pump IC which operates as a dc-to-dc power booster on the other layer. The combined system, fabricated on a single module as a system-on-package, implements the RF triggered PMU from which the $\mathrm{p}-\mathrm{i}-\mathrm{n}$ diodes are biased to reconfigure the SIR filter dynamically. Both the filter and the rectifier are fabricated using microstrip technology and the two layers share a common RF ground.

Theoretical formulation and implementation of the reconfigurable bandpass filter is presented in Section II. Designing of PIFA antenna, rectifier and the dc-to-dc power booster are elaborated with a discussion on simulated and measured results in Sections III, IV and V respectively. RF Triggered power management unit combined module implementation and results are discussed in Section VI. In Section VII, the experimental results of the wirelessly triggered dynamically reconfigurable single- to dual-band SIR filter are presented, while the findings are summarized in Section VIII of the paper.

\section{RECONFIGURABLE BANDPASS FILTER}

An RF triggered PMU is used to dynamically enable the dc power for the forward biasing of four $\mathrm{p}-\mathrm{i}-\mathrm{n}$ diodes that are used 
to convert the single-band SIR filter into a dual-band filter (see Fig. 1(a)). The coupled-line SIR filter operates at $2.45 \mathrm{GHz}$ and in the presence of a low power (as low as $-13 \mathrm{dBm}$ ) external $\mathrm{RF}$ signal at $1.6 \mathrm{GHz}$, received by an inverted-F antenna on the back side of the module, the filter behaves as a dual-band filter with an additional passband around $1.6 \mathrm{GHz}$. Both the reconfigurable filter with the full dc biasing network, and the rectenna with the cascaded dc-to-dc power booster are presented in Fig. 1(b)-(d), with the relevant geometrical dimensions shown in Table I.

\section{A. Single-Band BPF}

The initial layout configuration of the proposed reconfigurable BPF is shown in Fig. 2(a). It consists of four pairs of coupled-line sections and four connecting stepped impedance transmission lines. The one end of each coupled-line section is left open-ended, and the other end is connected to the transmission line with characteristic impedance $Z_{2}$. The corresponding electrical lengths and characteristic impedances of the elements used, are referred to as, $\theta_{1}, \theta_{2}, Z_{e}, Z_{o}$, and $Z_{2}$, as depicted in Fig. 2(a). $Z_{e}$, and $Z_{o}$, are the even- and odd- mode impedances of the coupled-line sections, and $Z_{2}$ is the characteristic impedance of the microstrip line with width $w_{f l}$ (see Fig. 1(c)). The proposed structure is symmetrical along both the vertical and horizontal axes so even- and odd-mode analysis is used to analyze the resonating modes. The even- and odd-mode equivalent circuits are shown in Fig 2(b)-(e) and the corresponding input impedance expressions are presented in (1)-(4) below.

Under even-even mode excitation, the circuit is bisected firstly along the vertical axis and subsequently along the horizontal axis and the ends are terminated with an open circuit, resulting in the equivalent circuit of Fig. 2(b), and an input impedance given by:

$$
Z_{\text {in,ee }}=-j Z_{e} \frac{Z_{e} Z_{2}-\tan \theta_{1} \tan \theta_{2}\left(Z_{2}^{2}+Z_{e}^{2}\right)-Z_{e} Z_{2} \tan ^{2} \theta_{1}}{2 Z_{2} Z_{e} \tan \theta_{1}+Z_{e}^{2} \tan \theta_{2}-Z_{2}^{2} \tan ^{2} \theta_{1} \tan \theta_{2}}
$$

Under odd-odd mode excitation, the equivalent circuit in Fig. 2(c) uses $Z_{o}$ in both ends, however, it is terminated with an open circuit as well (instead of a short circuit) because of the physical constraint of the open-ended coupled-lines. The equivalent impedance is given by:

$$
Z_{\text {in }, o o}=-j Z_{o} \frac{Z_{o} Z_{2}-\tan \theta_{1} \tan \theta_{2}\left(Z_{2}^{2}+Z_{o}^{2}\right)-Z_{o} Z_{2} \tan ^{2} \theta_{1}}{2 Z_{2} Z_{o} \tan \theta_{1}+Z_{o}^{2} \tan \theta_{2}-Z_{2}^{2} \tan ^{2} \theta_{1} \tan \theta_{2}}
$$

Similarly, the even-odd, and odd-even input impedances can be expressed as:

$$
\begin{gathered}
Z_{\text {in,eo }}=-j Z_{e} \frac{Z_{o} Z_{2}-\tan \theta_{1} \tan \theta_{2}\left(Z_{2}^{2}+Z_{e} Z_{o}\right)-Z_{e} Z_{2} \tan ^{2} \theta_{1}}{\left(Z_{e} Z_{2}+Z_{o} Z_{2}\right) \tan \theta_{1}+Z_{e} Z_{o} \tan \theta_{2}-Z_{2}^{2} \tan ^{2} \theta_{1} \tan \theta_{2}} \\
Z_{\text {in,oe }}=-j Z_{o} \frac{Z_{e} Z_{2}-\tan \theta_{1} \tan \theta_{2}\left(Z_{2}^{2}+Z_{e} Z_{o}\right)-Z_{o} Z_{2} \tan ^{2} \theta_{1}}{\left(Z_{e} Z_{2}+Z_{o} Z_{2}\right) \tan \theta_{1}+Z_{e} Z_{o} \tan \theta_{2}-Z_{2}^{2} \tan ^{2} \theta_{1} \tan \theta_{2}}
\end{gathered}
$$

The resonating modes of the structure can be calculated, by setting the denominator of each equivalent impedance, equal to zero. Evidently, $Z_{i n, e o}$ and $Z_{i n, o e}$ have identical denominators and thus the two modes $f_{e o}$ and $f_{o e}$ coincide. Consequently, three distinct resonating modes, $f_{e e}, f_{o o}$ and $f_{e o}=f_{o e}$ exist within the passband, having the relation $f_{o o}<f_{e o}<f_{e e}$, as can be clearly seen in the transmission response of the single-band BPF shown in Fig. 3.

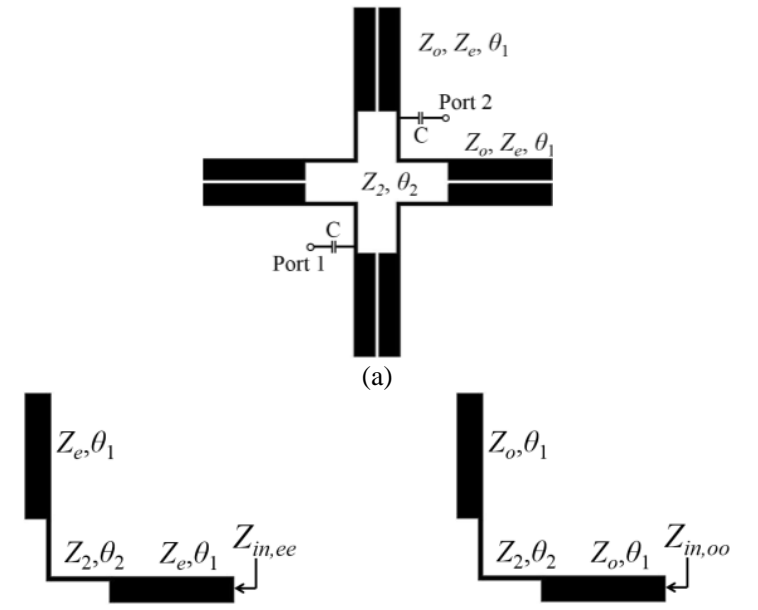

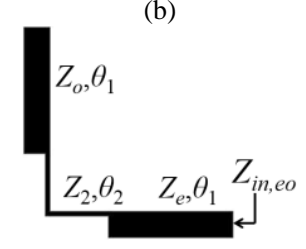

(d) (c)

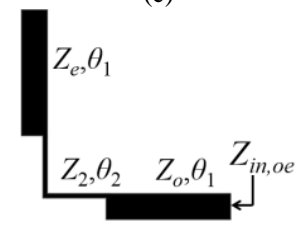

(e)
Fig. 2. (a) Layout configuration of the proposed single-band BPF. Equivalent circuits for single-band analysis: (b) even-even circuit, (c) odd-odd circuit, (d) even-odd circuit, and (e) odd-even circuit.

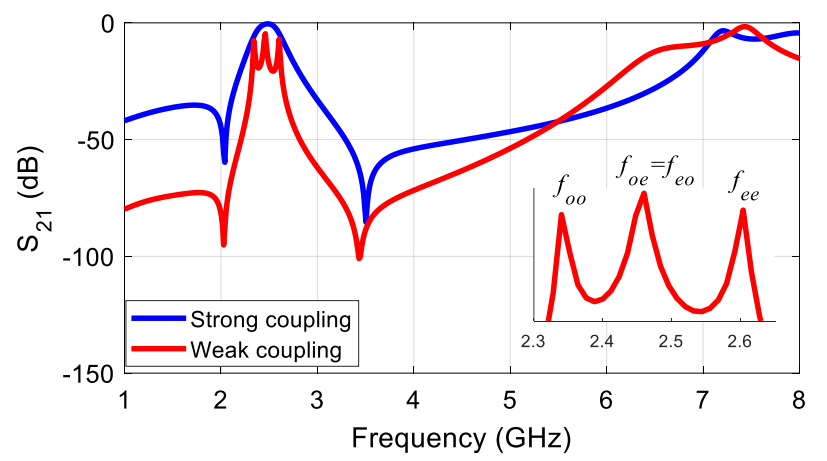

Fig. 3. $\left|S_{21}\right|$ comparison between weak and strong coupling for single-band BPF analysis.

Two identical lumped capacitors $(C)$ that are located at the input and output ports of the structure as shown in Fig. 2(a) are used to provide a weak and a strong coupling excitation. In order to study the resonating modes, the topology in Fig. 2(a) is simulated in Keysight's Advanced Design System (ADS). As a proof of concept, a BPF operating at $2.45 \mathrm{GHz}$ is designed with values of $\theta_{1}=40^{\circ}, \theta_{2}=46.4^{\circ}$ and characteristic impedances $Z_{e}$ $=58 \Omega, Z_{o}=36 \Omega$ and $Z_{2}=114 \Omega$. The corresponding frequency response for weak and strong excitation of the proposed filter is demonstrated in Fig. 3. In the simulated $\left|\mathbf{S}_{21}\right|$ for the weak coupling excitation it can be seen that two transmission zeros (TZs) are observed, one left of the passband at $2 \mathrm{GHz}$, and the other one at around $3.5 \mathrm{GHz}$. The three resonating modes are located in the range between 2.35 and $2.60 \mathrm{GHz}$ and in combination they contribute towards the creation of the singleband passband response with a simulated 3-dB fractional bandwidth of $15 \%$. 


\section{B. Dual-Band BPF}

Recent developments in microwave filters have focused in the design of dual-band BPFs since they are considered key devices with wide applications in the modern communication systems. Recently, there is an increasing industrial demand for novel dual-band BPFs and many approaches have been reported in the recent literature [26]-[29]. By electrically connecting the ends of two of the pairs of the coupled line sections, this can lead to a dual-band BPF with passband frequencies at $1.6 \mathrm{GHz}$ and $2.45 \mathrm{GHz}$. The layout configuration of the proposed dualband BPF is depicted in Fig. 4(a). Symmetry along the vertical and horizontal axes is used to analyze the resonating modes from the derived equivalent even- and odd-mode circuits which are given in Fig. 4(b)-(e), respectively.

Using a similar analysis as for the single-band case, the even-even, even-odd, odd-even and odd-odd input impedances can be expressed as:

$$
\begin{aligned}
& Z_{\text {in }, e e}=-j Z_{e} \frac{Z_{e} Z_{2}-\tan \theta_{1} \tan \theta_{2}\left(Z_{2}^{2}+Z_{e}^{2}\right)-Z_{e} Z_{2} \tan ^{2} \theta_{1}}{2 Z_{2} Z_{e} \tan \theta_{1}+Z_{e}^{2} \tan \theta_{2}-Z_{2}^{2} \tan ^{2} \theta_{1} \tan \theta_{2}} \\
& Z_{\text {in,eo }}=j Z_{e} \frac{\left(Z_{e} Z_{2}+Z_{o} Z_{2}\right) \tan \theta_{1}+Z_{1}^{2} \tan \theta_{2}-Z_{e} Z_{2} \tan ^{2} \theta_{2}}{Z_{e} Z_{2}-\tan \theta_{1} \tan \theta_{2}\left(Z_{2}^{2}+Z_{e} Z_{2}\right)-Z_{o} Z_{2} \tan ^{2} \theta_{1}} \\
& Z_{i n, o e}=-j Z_{o} \frac{Z_{e} Z_{2}-\tan \theta_{1} \tan \theta_{2}\left(Z_{2}^{2}+Z_{o} Z_{e}\right)-Z_{o} Z_{2} \tan ^{2} \theta_{1}}{\left(Z_{e} Z_{2}+Z_{o} Z_{2}\right) \tan \theta_{1}+Z_{o} Z_{e} \tan \theta_{2}-Z_{2}^{2} \tan ^{2} \theta_{1} \tan \theta_{2}} \\
& Z_{\text {in,oo }}=-j Z_{o} \frac{2 Z_{o} Z_{2} \tan \theta_{1}+Z_{2}^{2} \tan \theta_{2}-Z_{2}^{2} \tan ^{2} \theta_{1} \tan \theta_{2}}{Z_{o} Z_{2}-\tan \theta_{1} \tan \theta_{2}\left(Z_{o}^{2}+Z_{2}^{2}\right)-Z_{o} Z_{2} \tan ^{2} \theta_{1}}
\end{aligned}
$$

Therefore, four distinct resonating modes $f_{e e}, f_{o o}, f_{e o}$ and $f_{o e}$ are mathematically calculated by setting each of the four distinct denominators equal to zero. $f_{e e}$, and $f_{o e}$ remain the same compared to the respective modes derived from the single-band BPF. However, with the two pairs of coupled lines shorted, as a result of the diodes D1 and D2 set to the "ON" state, the equivalent circuits in Figs 4(c) and 4(e) are modified and the derived $f_{e o}$, and $f_{o o}$ appear below the left $\mathrm{TZ}(2 \mathrm{GHz})$, forming the second passband around $1.6 \mathrm{GHz}$. Consequently, the filter obtains two passbands and is converted into a dualband BPF. Fig. 5 displays the simulated results of the dual-band bandpass filter of Fig. 4(a) under weak and strong coupling excitation. It can be seen that the higher passband around 2.45 $\mathrm{GHz}$, which is formed from the $f_{o e}$ and $f_{e e}$ resonances, retains its center mostly unchanged but it has a bandwidth decrease as a result of the shift of $f_{o o}$ to the lower passband at $1.6 \mathrm{GHz}$. As the coupling is increased (i.e. strong coupling), a dual bandpass response is formed with the lower passband from $1.5-1.7 \mathrm{GHz}$ and the higher one from $2.4-2.53 \mathrm{GHz}$, with simulated $3 \mathrm{~dB}$ fractional bandwidths of $12.7 \%$ and $6.5 \%$, respectively. The bandwidths in both states cover all fourteen channels that are used in Europe (ETSI), North America (FCC) and Japan for 2.4 $\mathrm{GHz}$ Wi-Fi 802.11 Industrial, Scientific and Medical (ISM) band [30].

\section{Reconfigurable Filter Fabrication and Measurements}

Fig. 1(c) shows the schematic diagram of the proposed reconfigurable single-/dual-band BPF. Four Skyworks DSM8100-000 p-i-n diodes $\left(\mathrm{D}_{1}, \mathrm{D}_{2}, \mathrm{D}_{3}\right.$, and $\left.\mathrm{D}_{4}\right)$ are employed as shown to achieve the filter reconfigurability. Diodes $\mathrm{D}_{1}$ and $\mathrm{D}_{2}$ are placed at the ends of the two pairs of the coupled-line

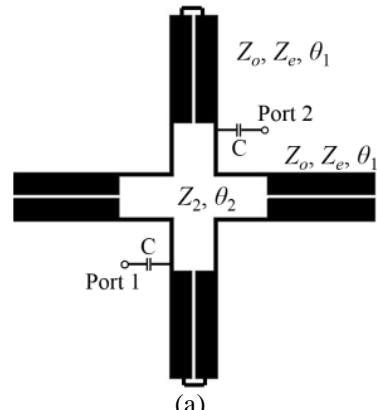

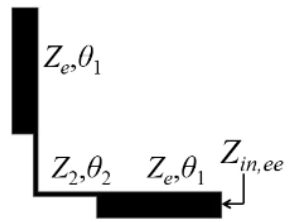

(b)

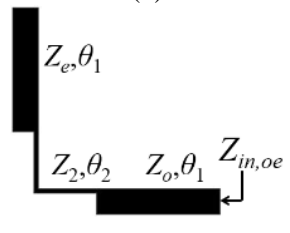

(d)

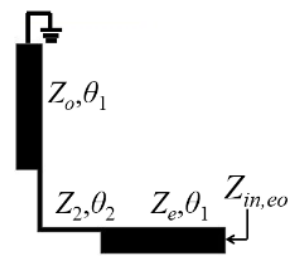

(c)

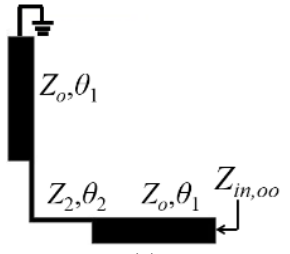

(e)
Fig. 4. (a) Layout configuration of the proposed dual-band BPF. Equivalent circuits for dual-band analysis: (b) even-even circuit, (c) even-odd circuit, (d) odd-even circuit, and (e) odd-odd circuit.

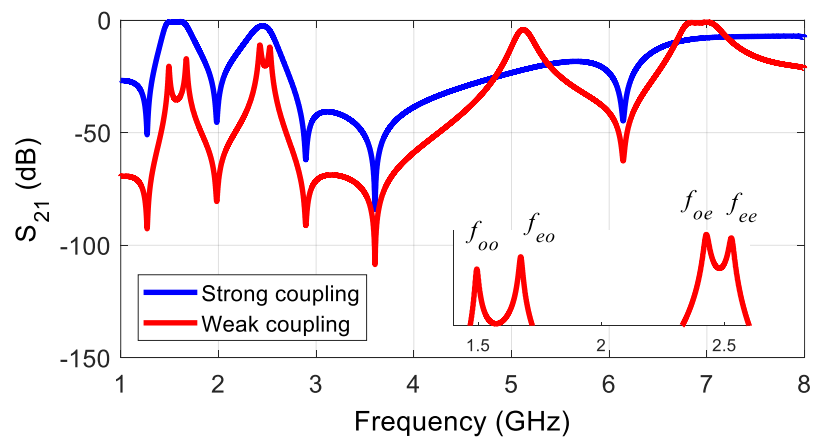

Fig. 5. $\left|\mathrm{S}_{21}\right|$ comparison between weak and strong coupling for the dual-band BPF analysis.

sections and are used to electrically connect or disconnect their open-ended edges, converting the open-ended coupled lines into shorted-ended coupled lines. Diodes $\mathrm{D}_{3}$ and $\mathrm{D}_{4}$, are used to increase the physical length of the open stubs, which are used for the spurious harmonics suppression. If a dual-band response is triggered from an ambient RF signal, all four diodes are forward biased using totally $40 \mathrm{~mA}$. When the diodes are in the "ON" state, $\mathrm{D}_{1}$ and $\mathrm{D}_{2}$ effectively join the edges of the coupled line sections whereas the other two diodes, $\mathrm{D}_{3}$ and $\mathrm{D}_{4}$ increase the physical lengths of the open stubs. On the other hand with the four diodes in the "OFF" state, the open stubs have shorter physical lengths and the coupled-line sections are left openended, thus causing a single-band response. The diodes have a low capacitance value of $0.025 \mathrm{pF}$ and a parasitic inductance of $0.7 \mathrm{nH}$. A simple bias circuitry is adopted where small square pads are introduced to connect to dc lines to host RF choke inductors $(82 \mathrm{nH})$. The dc biasing circuitry was carefully 


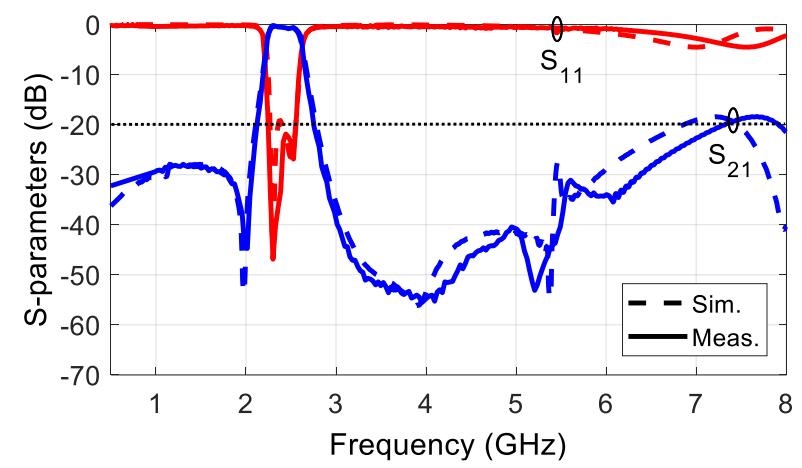

Fig. 6. Simulated and measured results of the reconfigurable filter when there is no RF triggering - Single-band BPF response.

designed to maintain the symmetry of the reconfigurable filter. The forward and reverse biasing of all $\mathrm{p}-\mathrm{i}-\mathrm{n}$ diodes is controlled through this dc biasing circuitry, which is connected to the output of the dc-to-dc power booster on the back side of the filter. As discussed above, the filter requires four diodes for successful single- to dual-band switching. The two states of operation are achieved with either all four diodes in the "OFF" state (single-band BPF) or all four diodes in the "ON" state (dual-band BPF).

The prototype filter is fabricated on a Rogers RO4003 substrate with relative dielectric constant $\varepsilon_{\mathrm{r}}=3.55$ and thickness $\mathrm{h}=0.813 \mathrm{~mm}$. The constituent feature dimensions are shown in Fig. 1 and the fabrication values are summarized in Table I. The overall size of the filter is $30.9 \times 33.7 \mathrm{~mm}^{2}$.

Simulations were carried out with the Ansys High Frequency Structure Simulation (HFSS) v15.0 software and an Agilent E8363B VNA was used for measurements. Fig. 6 shows the simulated and measured S-parameters when all four p-i-n diodes are in the "OFF" state. According to Fig. 6, only one passband is obtained with a measured fractional bandwidth of $15 \%$. Results with all p-i-n diodes in the "ON" state are depicted in Fig. 7. It can be seen that the proposed filter can dynamically operate at $1.6 \mathrm{GHz}$ and $2.45 \mathrm{GHz}$, providing measured fractional bandwidths of $12.7 \%$ for the lower and $6.5 \%$ for the upper passband. It can be observed that the simulated and measured results are in very good agreement. Note that the measured results presented in Fig. 6 and 7 correspond to the filter backed with RF Triggered PMU combined module, which will be discussed in detail in Section VII.

For the single-band BPF, the measured insertion loss and return loss within the passband is less than $0.85 \mathrm{~dB}$ and greater than $19 \mathrm{~dB}$, respectively, with the upper stopband extended up to $3.05 \times f_{o}\left(f_{o}\right.$ is the center frequency of the higher passband) for suppression levels greater than $20 \mathrm{~dB}$. Furthermore, the measured results for the lower passband of the dual-band filter demonstrate an insertion loss and return loss lower than $1.2 \mathrm{~dB}$ and higher than $18.6 \mathrm{~dB}$, respectively. At the same time, for the upper passband, the insertion loss is better than $0.69 \mathrm{~dB}$ and the return loss is greater than $23.36 \mathrm{~dB}$. The upper stopband for the dual-band BPF was extended up to $3.03 \times f_{o}$ for suppression levels greater than $20 \mathrm{~dB}$.

The RF triggered PMU is fabricated on the back side of the filter as shown in Fig. 1(b). The received RF signal is rectified

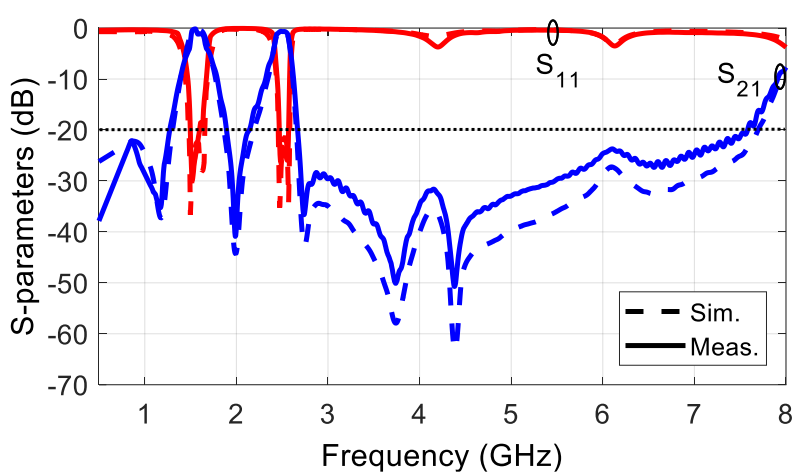

Fig. 7. Simulated and measured results of the reconfigurable filter when RF triggering occurs - Dual-band BPF response.

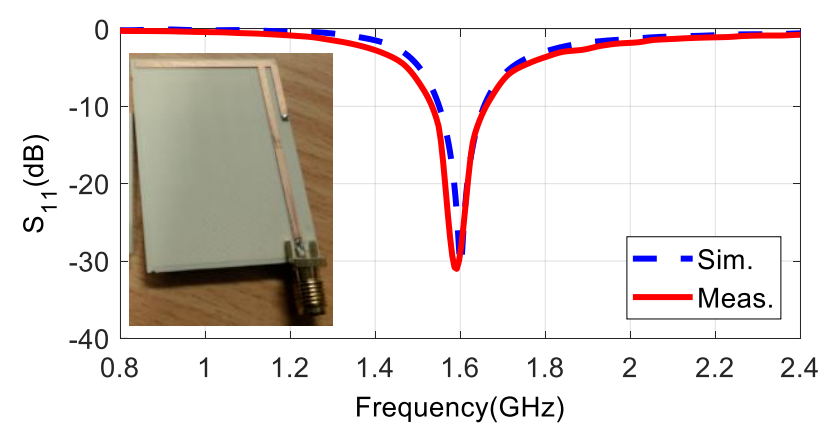

Fig. 8. Simulated and measured reflection coefficient for the PIFA antenna. The fabricated stand-alone prototype of the antenna is shown in the inset.

and then used as a triggering signal in order to enable through the dc-to-dc power booster the actuation of the four p-i-n diodes, and thus the dynamic reconfigurability the SIR filter. It will be shown in sections III and IV that the minimum received power at the antenna is required to be higher thatn $-13 \mathrm{dBm}$ in order to successfully implement the aforementioned dynamic reconfigurability.

\section{ANTENNA DESIGN}

The antenna for the power scavenging system had to be selected such as to accommodate the dual-layer microstrip technology and to provide a compact, yet effective design for efficient reception of the $1.6 \mathrm{GHz}$ RF signal. The selection of the antenna type was decided based on the available space, the size constraints of the reconfigurable filter, and the desired efficiency of the subsequently cascaded rectifier. After thorough investigation, a standard planar inverted-F antenna (PIFA) [31], [32] operating at $1.6 \mathrm{GHz}$ was designed (Fig. 8) and was demonstrated to serve the power scavenging part of the $\mathrm{RF}$ triggered PMU adequately. The physical dimensions of the antenna were chosen considering that it should share a common $\mathrm{RF}$ ground with the microstrip filter (on the available space behind the filter), and a rectifier and a dc-to-dc power booster should also be accommodated in a single module. A PIFA consisting of a planar strip of width $w_{a l}=1.6 \mathrm{~mm}$, parallel to the ground plane edge and shorted to the ground plane in one end was designed on ANSYS HFSS v15.0. The substrate used for antenna was same as the substrate used for filter design (Rogers RO4003). The primary design goal was high radiation 
efficiency using a compact $\left(44.7 \times 33.9 \mathrm{~mm}^{2}\right)$ substrate area. The ground shortening [31] of the PIFA antenna section allowed the antenna to be electrically small, hence a resonance frequency of $1.6 \mathrm{GHz}$ was achieved with an electrically small radiator $(\sim 0.15 \lambda)$. The feeding point of the antenna was selected keeping in mind that it needs to be connected directly to the rectifier. To test the stand-alone antenna, a $50 \Omega$ transmission line was designed and it was extended to the one end of the substrate board, where an SMA connector was mounted for the Sparameter measurements of the antenna in order to verify its reliable performance before it was used as a part of the system. Fig. 8 shows the picture of the fabricated PIFA along with the simulated and measured $\left|S_{11}\right|$, where the agreement between the simulation and measurement can be observed. The $\left|S_{11}\right|<-10$ $\mathrm{dB}$ bandwidth of the antenna, lies within the range of 1.55-1.64 $\mathrm{GHz}$.

\section{RECTIFIER}

The design of the rectifier had to accommodate a number of restrictions originating from the preceding PIFA, the nonconstant input impedance of the subsequent dc-to-dc power booster and the limited available space. A voltage doubler topology was preferred in an attempt to maintain low cost and a compact size at the expense of efficiency [33]. The desired characteristics of the rectifier included the highest possible RFto-dc efficiency for a wide range of RF input power levels ( -25 $\mathrm{dBm}$ to $0 \mathrm{dBm}$ ), good matching at the same input power range and compact design. The RF-to-dc efficiency which has a nonlinear dependence on the termination load, was optimized for a fixed load of $R_{L}=5.1 \mathrm{~K} \Omega$ derived from the data sheet of the subsequent dc-to-dc power booster.

The rectifier was designed at $1.6 \mathrm{GHz}$ keeping in mind the lower passband of the dual-band reconfigurable filter. Keysight -ADS was used to design the microstrip traces of the rectifier. S-parameter models were imported into the ADS library in order to accurately model the required lumped components and their associated parasitics. The same RO4003C substrate that was used for the filter in Section II and for the antenna in Section III was used. Large scale signal analysis in ADS and harmonic balance simulations were used. A linear power sweep was applied from $-50 \mathrm{dBm}$ to $0 \mathrm{dBm}$ considering the possible range of power levels of the RF scavenged signal.

The rectifier should be well matched with the $50 \Omega$ input impedance of the receiver antenna according to (9), and at the same time, it should perform with a high RF-to-dc efficiency at the available power range, according to (10), for a varying load $R_{L}$.

$$
\begin{gathered}
\Gamma=\frac{Z_{\text {in }}-50}{Z_{\text {in }}+50} \\
\eta=\frac{P_{\text {out }}}{P_{\text {in }}}=\frac{V_{d c}^{2} / R_{L}}{P_{\text {in }}}
\end{gathered}
$$

Here, $Z_{\text {in }}$ is the impedance at the input terminal of the rectifier, $P_{\text {in }}$ and $P_{\text {out }}$ are the input and output power levels respectively, and $V_{d c}$ is the voltage across the load resistance $R_{L}$ which is the input impedance of the cascaded power booster, which in turn

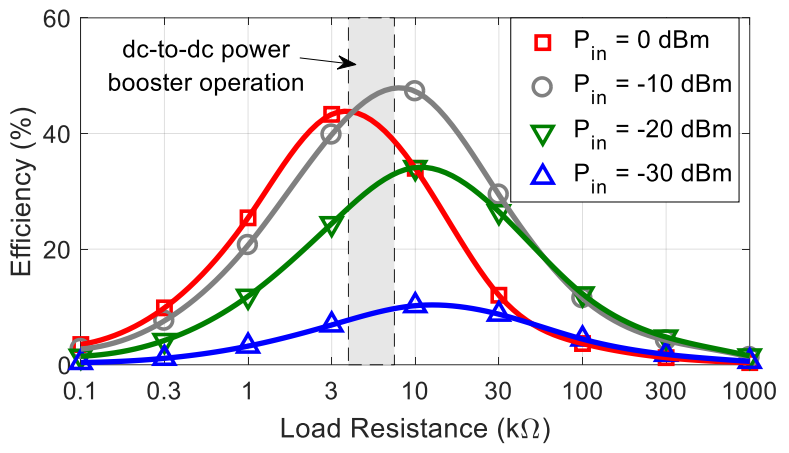

Fig. 9. Simulated rectifier efficiency (curve fitting) versus output load for multiple power input levels at $1.6 \mathrm{GHz}$.

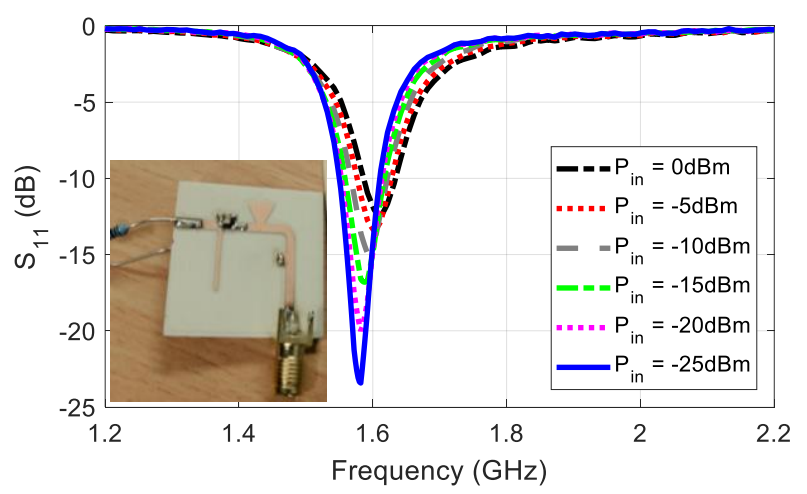

Fig. 10. Measured reflection coefficient of the rectifier at different power levels. The standalone fabricated prototype of the rectifier is shown in the inset.

depends on the biasing conditions.

The efficiency of the rectifier is non-linearly dependent on the termination load, the resistance $R_{L}$. On the other hand, as it will be elaborated in the subsequent Section V, the impedance of the power booster is dependent on both the enabling voltage $V_{E N}$ and the $V_{C C}$ biasing voltage. Before cascading the rectifier with the power booster, the effect on the rectifier efficiency when $R_{L}$ changed has to be investigated. An analysis was carried out, in which $R_{L}$ was varied from $100 \Omega$ to $1 \mathrm{M} \Omega$. Fig. 9 shows the plots of the simulated efficiency for multiple input power levels vs load $R_{L}$. A logarithmic scale is used for the $R_{L}$ values. Fig. 9 indicates that within the range from $4205-6700$ $\Omega$ which is the actual range for the measured $R_{L}$ values on the dc-to-dc active power booster, the rectifier operates close to its maximum efficiency region for various input power levels.

For the rectifier design, initially, a standard voltage doubler was designed along a $50 \Omega$ microstrip line at $1.6 \mathrm{GHz}$. Two problems were encountered: a) the bandwidth of the rectifier was very narrow and as a result good matching within the entire input power range could not be maintained, and $b$ ) as a result of the relatively low operation frequency of the rectifier, the physical size of the rectifier features (especially $l_{t}, l_{s l}$ and $l_{s 2}$ ) was too large to fit in the available space.

To overcome the first problem, a radial stub was introduced instead of linear open stub. As shown in Fig. 1(d), the rectifier circuit begins from the end of the receiver antenna, and a curved transmission line section hosts the shorted stub and a radial stub 
placed at the point where sufficient area was available. This rectifier shape and dimensions were dictated based on the results of a multivariable optimization in ADS. A quasi-Newton algorithm was used with two output goals: a) $\left|\mathrm{S}_{11}\right|<-15 \mathrm{~dB}$ at $1.6 \mathrm{GHz}$, and b) maximum possible RF-to-dc efficiency. Subsequently and for the given rectifier traces, capacitances $C_{01}$ and $C_{02}$ were re-optimized considering the available lumped component values from the Murata component library [34]. In addition to this, during every optimization step, the $\left|S_{11}\right|$ of the rectifier at discrete input power levels ( -25 to $-10 \mathrm{dBm}$ ) was carefully observed to ensure acceptable matching within the targeted power range. The final values of the capacitors used, were: $C_{01}=139 \mathrm{pF}$ and $C_{02}=150 \mathrm{pF}$. The photograph of the rectifier is presented in the inset of Fig. 10 and the fabricated set of feature values is summarized in Table I. The rectifier was designed and tested separately as a stand-alone device before using as part of the entire RF triggered PMU. Fig. 10 shows that the $\left|S_{11}\right|$ is below $-10 \mathrm{~dB}$ from 1.57 to $1.61 \mathrm{GHz}$, giving a measured bandwidth of $40 \mathrm{MHz}$. The measured efficiency of the rectifier was calculated by measuring the dc voltage across $R_{L}$ while changing the input power level $P_{\text {in }}$ from a signal generator (Rohde \& Schwarz SMF100A) at $1.6 \mathrm{GHz}$. The waveform used in this experiment was an unmodulated sine wave. The power level was varied from $-25 \mathrm{dBm}$ to $0 \mathrm{dBm}$ with a step size of $2.5 \mathrm{dBm}$. The simulated and measured output voltage across $R_{L}=5.1 \mathrm{~K} \Omega$ is shown in Fig. 11. Equation (10) was used to calculate the measured efficiency of the rectifier, presented in Fig. 11 vs the $P_{i n}$. It is important to point out that the efficiency of the rectifier depends not only on the performance of voltage doubler circuit, but also on the quality of impedance matching at the input terminal of the rectifier. The final parameters presented in Table I ensure an optimized matching condition as well as maximum achievable efficiency of the rectifier at a given $P_{i n}$. The design strategy for the matching network takes into consideration both the timedependent nature of the power booster's switching operation, and the time-varying RF actuation signal received by the PIFA. To describe this, let us look at the rectifier performance at a static $P_{\text {in }}$ condition. Fig. 12(a) shows the dependence of $V_{\text {rect }}$, and $I_{\text {rect }}$ on the optimal $P_{\text {rect }}$ at the varying load $R_{L}$ at $P_{\text {in }}=31.6$ $\mu \mathrm{W}(-15 \mathrm{dBm})$. The operation of the device resides where $\mathrm{V}$ and I combination is $\sim 0.31 \mathrm{~V}$ and $\sim 60 \mu \mathrm{A}$ respectively, which is very close to the ideal power condition of any $V_{\text {rect }}, I_{\text {rect }}$ combination. Fig. 12(b) shows the simulated efficiency as a two-variable function, depending at any time from $P_{\text {in }}$ and $R_{L}$ non-linearly. An in-depth discussion on this is presented in Section VI. The measured and simulated results are in good agreement. From Fig. 12, it can be seen that the efficiency of the rectifier increases from $20 \%$ to $49 \%$ when the input power level increases from $-25 \mathrm{dBm}$ to $-10 \mathrm{dBm}$. For the critical -13 $\mathrm{dBm}$ input power required for the $\mathrm{p}-\mathrm{i}-\mathrm{n}$ diode biasing, the

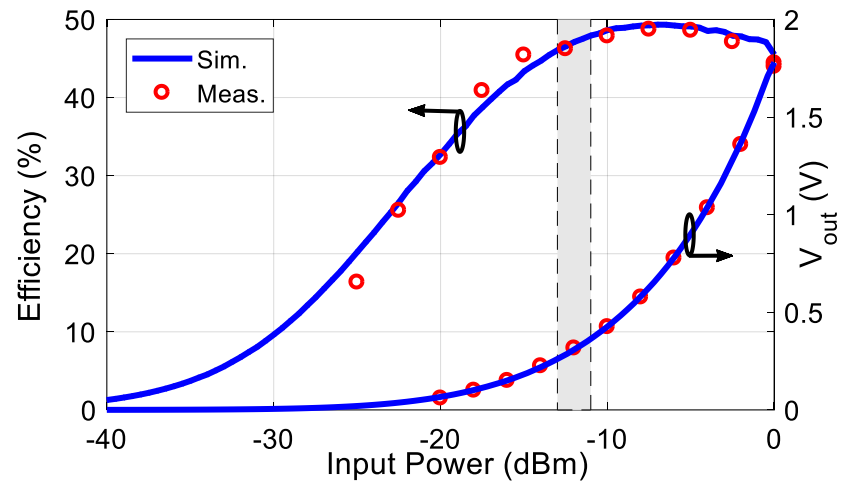

Fig. 11. Simulated and measured rectifier output voltage and the efficiency across the $5.1 \mathrm{~K} \Omega$ load at $1.6 \mathrm{GHz}$ versus the input power.

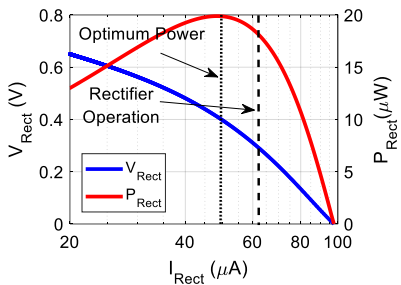

(a)

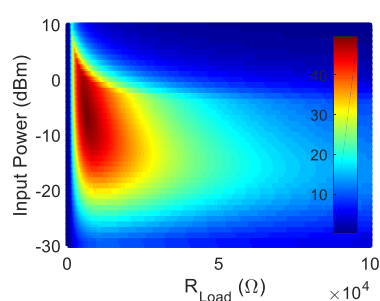

(b)
Fig. 12 (a) Load current consumption versus Vrect and Prect at Pin $=-15$ $\mathrm{dBm}$ (b) Rectifier efficiency for combined Pin and $R L$ variations. Both results are based on simulations.

TABLE II

RF-TO-DC CONVERSION EFFICIENCY VERSUS FREQUENCY AND INPUT POWER

\begin{tabular}{cccc}
\hline \hline Ref. & Freq. $(\mathrm{GHz})$ & $P_{\text {in }}(\mathrm{dBm})$ & Efficiency \\
\hline This work & 1.60 & $-25,-10$ & $16.5 \%, 49.0 \%$ \\
{$[12]$} & 0.85 & $-20,-10$ & $20 \%, 37 \%$ \\
{$[13]$} & 0.85 & $-20,-10$ & $20.5 \%, 35.3 \%$ \\
{$[14]$} & 1.85 & -20 & $15.0 \%$ \\
{$[15]$} & 2.45 & -20 & $15.0 \%$ \\
{$[16]$} & $0.47-0.77$ & $-40,-20$ & $0.4 \%, 18.2 \%$ \\
{$[18]$} & 2.45 & 25 & $65.0 \%$ \\
{$[24]$} & $0.90,1.75$ & $-8.77,-16.27$ & $44.5 \%, 34.5 \%$ \\
{$[25]$} & 0.90 & -10 & $33.0 \%$ \\
{$[35]$} & 0.86 & $-25,-10$ & $17 \%, 44.0 \%$ \\
{$[36]$} & 2.45 & -17.2 & $50.0 \%$ \\
\hline
\end{tabular}

efficiency is $47 \%$ and the output voltage $0.43 \mathrm{~V}$. The rectifier has been tested using a single tone signal at $1.6 \mathrm{GHz}$ to ensure fair comparison with the referenced rectifier designs summarized in Table II. It can be observed that the proposed rectifier compares favorably with other recently reported designs.

\section{DC-TO-DC POWER BOOSTER}

The proposed dynamically reconfigurable dual-band filter requires four $\mathrm{p}-\mathrm{i}-\mathrm{n}$ diodes to achieve the desired reconfigurability. To actuate a single $\mathrm{p}-\mathrm{i}-\mathrm{n}$ diode (Skyworks SMP1345), a minimum power of $9 \mathrm{~mW}$ is required, since around a $0.89 \mathrm{~V}$ voltage and $10 \mathrm{~mA}$ current are needed for each diode. The four $\mathrm{p}-\mathrm{i}-\mathrm{n}$ diodes are simultaneously set in the "ON" state, therefore a total of $36 \mathrm{~mW}(15.6 \mathrm{dBm})$ of dc power is required. For realistic wirelessly received RF power levels, the amount of harvested dc power from the rectifier output is not sufficient to directly actuate the $\mathrm{p}$-i-n diodes, therefore an active 


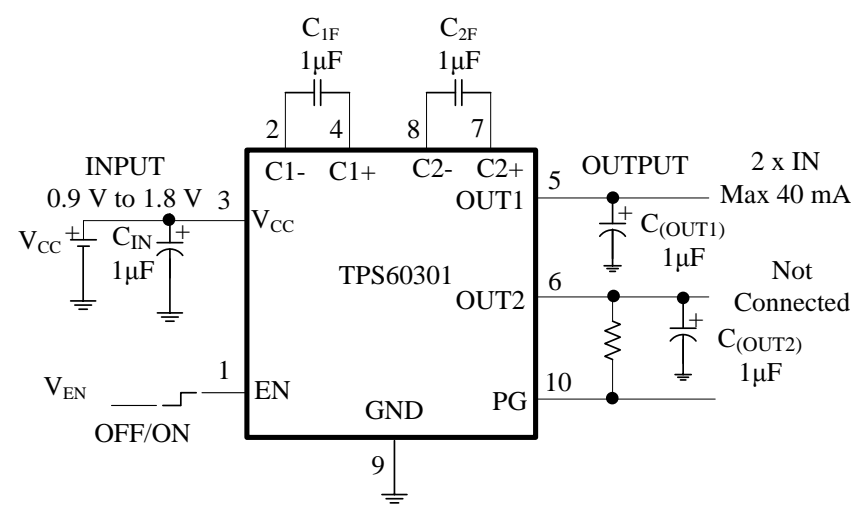

Fig. 13. Schematic of the dc-to-dc active power booster designed using the charge pump IC model: TPS60301.

dc-to-dc power booster is introduced. The device is able to convert dc voltage from a lower level to a higher level, when an enabling voltage signal is above a threshold. A charge pump Integrated Circuit (IC) model: TPS60301 [37] with dual output, from Texas Instruments is used, as is shown in Fig. 13. The charge pump requires a dc voltage supply, $V_{C C}$ between $0.9 \mathrm{~V}$ and $1.8 \mathrm{~V}$. It has a logic controlled input (enabling input $V_{E N}$ ) and delivers an output $\left(V_{\text {OUTI }}\right)$ dc voltage approximately two times the $V_{C C}$ voltage. Only one of the two available output terminals of the IC is used, while the second terminal remains unconnected. Along with this IC, five $1 \mu \mathrm{F}$ capacitors are used. The capacitors are required to build a complete high efficiency charge pump dc-to-dc power booster (sometimes also referred to as a boost converter) as can be seen in the schematic of Fig. 13. In this schematic, $C_{I F}$ and $C_{2 F}$ are used as flying capacitors, while, $C_{(\text {OUTI })}, C_{(\text {OUT2) }}$ and $C_{I N}$ are used as filter capacitors that bypass any pulse or noise to the ground. For every combination of the varying operating conditions of the active dc-to-dc power booster, (i.e. $V_{C C}$ ranging from $0.9-1.8 \mathrm{~V}$ and $V_{E N}$ ranging from $0.0-1.5 \mathrm{~V})$, the measured input impedance $\left(R_{L}\right.$ termination load for the preceding rectifier) of the dc-to-dc power booster, as measured between the EN and GND terminals, remains between $4205 \Omega$ and $6700 \Omega$.

When $\mathrm{V}_{\mathrm{EN}}$ is "high" and OUT2 (terminal 6) is not connected, OUT1 (terminal 5) can deliver a maximum of $40 \mathrm{~mA}$ and approximately two times the $V_{C C}$ voltage. The device is enabled when $\mathrm{V}_{\mathrm{EN}}$ is set from logic "low" $\left(<0.5 \times V_{C C}\right)$ to logic "high" $\left(>0.5 \times V_{C C}\right)$. Considering that the minimum required $V_{C C}$ is $0.9 \mathrm{~V}$, this means that a minimum of $0.45 \mathrm{~V}$ is needed from the output of the rectifier in order to make the power at the terminal OUT1 available to the $\mathrm{p}-\mathrm{i}-\mathrm{n}$ diodes. Measurements presented in Section VII indicated that this minimum enabling voltage was actually 0.43 V. From Fig. 11, the required received RF power from the rectifier has to be higher than $-13 \mathrm{dBm}$. For the rectifier's converted voltage calculation, the power booster's input impedance was approximated to be $5.1 \mathrm{~K} \Omega$. Experimentally, with the input RF power controlled from a signal generator (R\&S SMF100A) directly feeding the rectifier, the diodes were successfully forward biased with as low as -13 $\mathrm{dBm}$ RF power. The power booster first enters a dc start-up mode during which the flying capacitor $C_{\text {OUTI }}$ will charge up to $\sim V_{C C}$. After that, the charge pump IC starts switching to boost the voltage further up to about two times $V_{C C}$. When $V_{E N}$ goes back to logic "low", it disables all internal circuits, and consequently it reduces the output current to only $0.05 \mu \mathrm{A}$. The device exits the "shutdown state" once $V_{E N}$ is set to logic "high" again. The typical no-load, start-up time of the power booster is $400 \mu \mathrm{s}$.

\section{RF TRIGGERED PMU COMBINED MODULE}

The inverted-F antenna from Section III is connected to the rectifier from Section IV forming a rectenna, and subsequently the rectenna is connected to the active dc-to-dc power booster that operates as a power management unit. The related theoretical analysis is thoroughly addressed in [38]-[39] and references therein. The theoretical principals of PIFA design can be found in the classical literature [40]-[41]. The combined module can be considered an RF triggered PMU since the rectified input $\mathrm{RF}$ signal is used to enable the delivery of the dc power to the four $\mathrm{p}-\mathrm{i}-\mathrm{n}$ diodes used for the dynamic reconfiguration of the SIR single-band/dual-band BPF presented in Section II. The power for the forward biasing of the four $\mathrm{p}-\mathrm{i}-\mathrm{n}$ diode switches is provided from the active power booster. In the previous sections, the antenna, the rectifier and the dc-to-dc power booster were discussed independently as stand-alone devices. This section discusses the combined RF triggered PMU system presented in Fig. 1(d) where the constituent components are combined into a single module.

In [35] it was shown that, the variation of the input power level may affect the matching, and the $-10 \mathrm{~dB}$ bandwidth may actually shift away from the design frequency. Therefore, it is important to ensure good impedance matching between the antenna and the rectifier for multiple power levels. The optimization conditions mentioned in Section IV and the consequent geometrical parameters met this condition. In Fig. 10 , the measured $\left|S_{11}\right|$ plots of the rectifier are compared when the input power levels vary from -25 to $-10 \mathrm{dBm}$. The rectifier operational bandwidth $\left(\left|\mathrm{S}_{11}\right|<-10 \mathrm{~dB}\right)$ is observed to be within $1.576-1.628 \mathrm{GHz}, 1.558-1.618 \mathrm{GHz}$ and $1.550-1.611 \mathrm{GHz}$ for input power levels of $-5,-15$ and $-25 \mathrm{dBm}$, respectively, ensuring that the rectenna is well matched for all the related power levels. Moreover, the measured $R_{L}$ values (4205 - 6700 $\Omega$ ) which correspond to the input impedance of the dc-to-dc power booster under the required biasing conditions are fairly close to the impedances for which the maxima of the efficiency plots are observed (Fig. 9).

Consequently the implemented combined module ensures the successful operation for a broad and practically time varying range of input power levels, and for considerably varying $R_{L}$ values, despite the rectifier's non-linear dependence on both $P_{\text {in }}$ and $R_{L}$ parameters, as defined in (10).

The practically available $1.6 \mathrm{GHz}$ signals include both LongTerm Evolution (LTE) B24 signals and commercial Global Positioning System (GPS) signals. Any received 1.6 GHz signal is processed in baseband using a Digital Signal processor (DSP) processor. If the received signal is classified as undesired a digital "flag" control signal will be generated, " 0 ", and will be directed through an AND gate in the EN pin of the TPS60301 circuit. This way if the DSP controller does not classify the 
signal as desired the filter will not allow the second passband. However if the signal is classified as desired the combination of the generated " 1 " in the AND gate will allow the passband at $1.6 \mathrm{GHz}$. Note that the power level of LTE B24 signals and GPS signals differ by orders of magnitude. While the GPS signal level is around $-120 \mathrm{dBm}$ (below the minimum power that can be detected or rectified by the rectifier), LTE B24 [42] (1600 L-band having 1626.5 - $1660.5 \mathrm{MHz}$ uplink and 1525 $1559 \mathrm{MHz}$ downlink) with a Base Station (BS) EIRP of $+31.9 \mathrm{dBW} / 200 \mathrm{KHz}$ is practically adequate (assuming ideal free space propagation conditions) for triggering the power booster several meters away from the transmitter. Although the presented work is a proof of concept of a novel approach for dynamically reconfigurable passives, the filter was designed for the LTE B24/GPS (1.6 GHz) bands and the Wi-Fi $(2.4 \mathrm{GHz})$ band and it could be exploited by any everyday device (tablet, cellphone) that uses both these applications.

\section{IMPLEMENTATION AND TESTING}

Photographs of the fabricated prototype of the proposed dynamically reconfigurable SIR filter are presented in Fig. 14. Fig. 14(a) shows the top view of the module where the filter is realized, and Fig. 14(b) shows the rear view where the RF triggered PMU module is built. For the fabrication, two Rogers RO4003C boards were used which were placed back to back having a common RF ground. On the first board the filter was fabricated and the $\mathrm{p}-\mathrm{i}$-n diodes and the RF choke inductors were soldered (Fig 14(a)). On the second board, the antenna, the rectifier's microstrip traces and the dc circuit footprint for the charge pump IC and its peripherals were created using an LPKF ProtoMat H100 milling machine. Both the rectifier's matching stubs and the PIFA were shorted to the common RF ground using vias through $0.4 \mathrm{~mm}$ diameter holes. The exact physical locations of the vias are presented as red dots in Fig. 1(d). Then, on both sides of the module the required lumped components were soldered. P-i-n diodes (Skyworks DSM8100-000 [43]), and RF choke inductors (Coilcraft series 0402CS-82 nH [44]) were used for the reconfigurable filter. Schottky diodes (Skyworks SMS7630-079LF [45]) and capacitors (Murata series GJM03-139 pF and $150 \mathrm{pF}$ [34]) were used for the rectifier and finally a charge pump IC (Texas Instruments TPS60301) with five capacitors (Murata series GJM03-1 $\mu \mathrm{F}$ [34]) was used for the power booster implementation. The dc circuit associated to the RF triggered PMU module is shown Fig. 1(d). Metallic pads indicated in the annotations used for wire soldering corresponds to the IC pin configuration and PCB layout [37]. SMA connectors were attached in order to measure the filter's S-parameters. Insulated wires were used to connect the OUT1 terminal of the IC to the biasing pads on the filter board side. Finally, the two boards were attached back-to-back so that the RF ground layers of both boards coincided with each other. Low loss glue was used to ensure adhesiveness between the two joint boards in order to realize a single module of the dual-layer dynamically reconfigurable single- to dual-band SIR filter with an integrated RF triggered PMU.

The measurement setup, implemented in order to evaluate the performance of the device under test (DUT), is presented in Fig. 15. Initially, a signal generator was connected to a replica of the

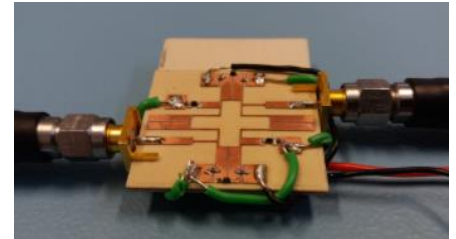

(a)

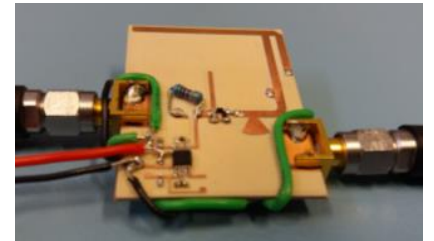

(b)
Fig. 14. Fabricated prototype of the DUT (a) Top view showing the dynamically reconfigurable SIR BPF filter, and (b) rear view showing the RF triggered PMU.

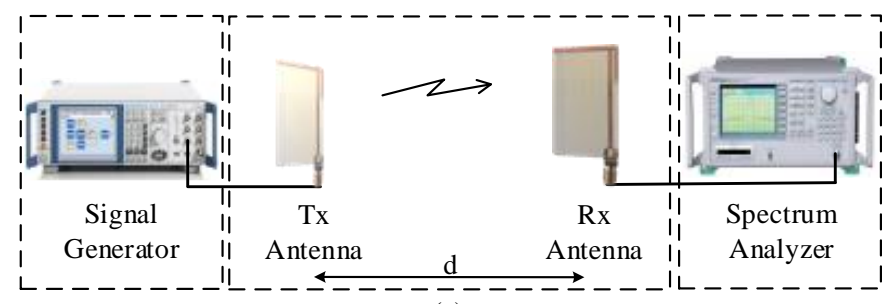

(a)

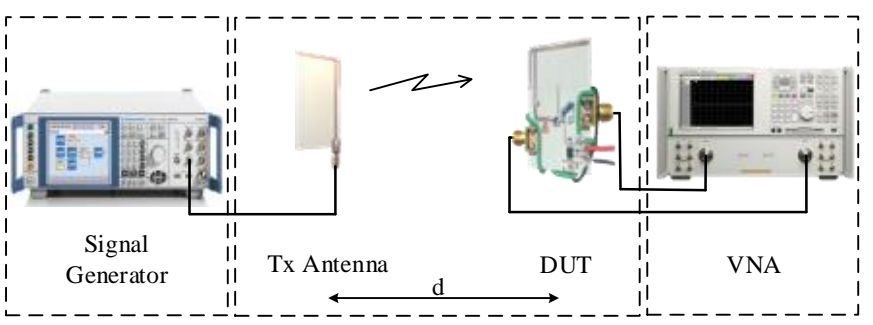

(b)

Fig. 15. Measurement process setup: (a) signal generator-transmitter PIFA and receiver PIFA-spectrum analyzer (b) signal generator- receiver antenna and DUT connected with VNA.

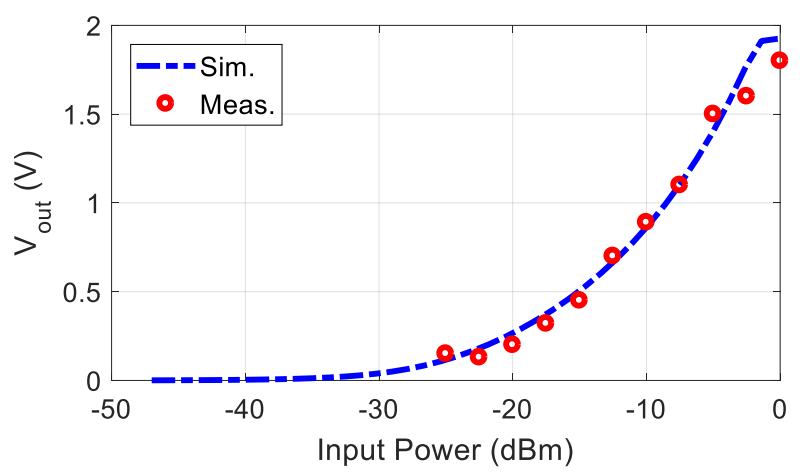

Fig. 16. Simulated and measured open-circuit voltage at the rectifier output terminal versus input power.

PIFA antenna and was used as a transmitter antenna. A second identical antenna was used as a receiver antenna and was connected to a spectrum analyzer (Anritsu MS2668C). Note that the transmitter PIFA in this experiment was only used because of its availability. Any antenna type with a known gain can be used to repeat the same experimental setup. The received power was measured while the distance between two antennas " $d$ " was recorded to create a set of distances with the corresponding RF $P_{\text {in }}$ levels at the input of the rectifier. Next, the receiver antenna and the spectrum analyzer were removed, and replaced with the rectenna. The open circuit voltage at the output terminal of the rectifier was measured, for the same set 


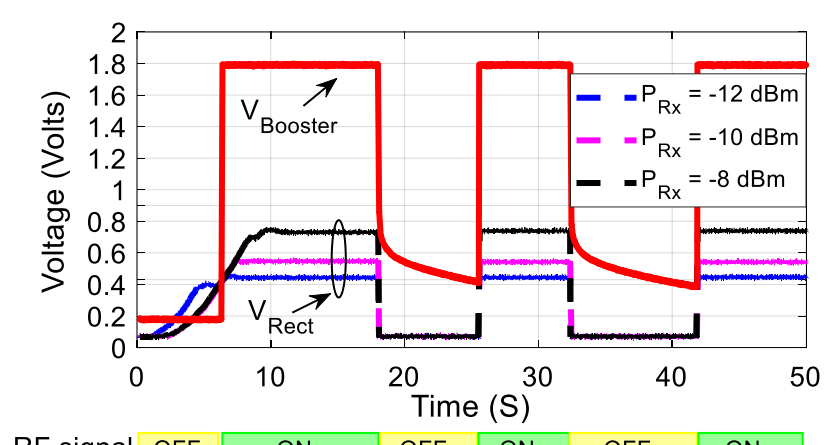

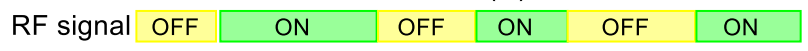

(a)

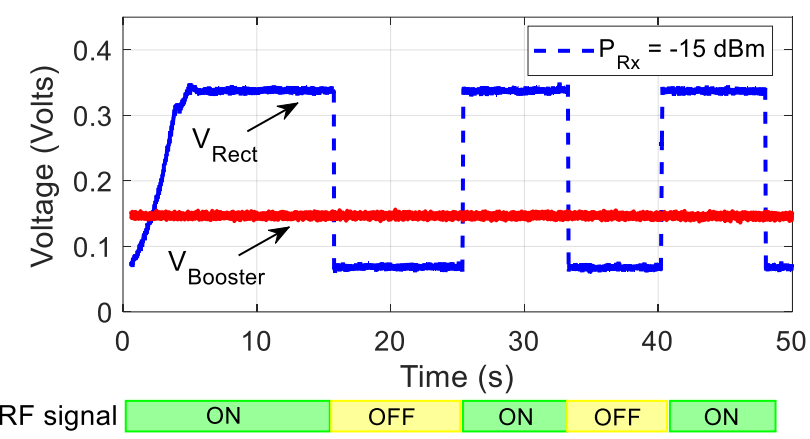

(b)

Fig. 17. (a) Measured voltages at the output terminals of the rectifier $\left(V_{\text {Rect }}\right)$ and the dc-to-dc power booster $\left(V_{B o o s t e r}\right)$ at multiple power levels. (b) $V_{\text {Rect }}$ and $V_{B o o s t e r}$ at received power $\left(P_{R x}=-15 \mathrm{dBm}\right)$ below the minimum required power level (i.e. $-13 \mathrm{dBm}$ ) for the diodes biasing.

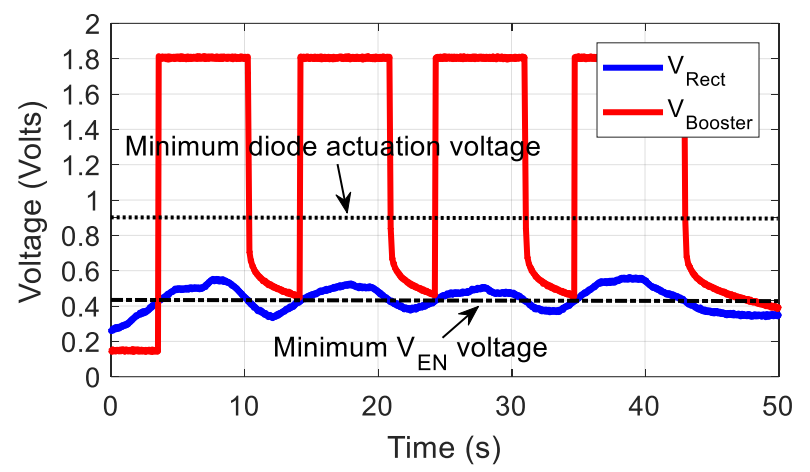

Fig. 18. Measured voltage across the rectifier and dc-to-dc power booster terminal with continuously varying transmitter - rectenna distance. The transmitted power (Signal generator power) was $15 \mathrm{dBm}$.

of distances. The measured open-circuit voltages were compared with the simulated results and the data is presented in Fig. 16. The reason of measuring the open circuit voltage was to verify the measurements with simulation before connecting the rectenna to the power booster. In the next step, a power booster circuit, implemented on a breadboard was connected at the output terminal of the rectifier in order to verify the anticipated RF triggering and consequently the biasing of the p$\mathrm{i}-\mathrm{n}$ diodes and the reconfiguration of the filter. During the measurements process, it was observed that when the output voltage of the rectifier (which is also the driving voltage $V_{E N}$ of the power booster) goes above $0.43 \mathrm{~V}$, the power booster successfully actuated all four $\mathrm{p}-\mathrm{i}-\mathrm{n}$ diodes of the filter. The measured $0.43 \mathrm{~V}$ voltage is slightly smaller than the expected
TABLE III

DUT MEASUREMENTS SUMMARY

\begin{tabular}{c|ccccc}
\hline \hline \multicolumn{7}{c}{ Signal generator power: 15 dBm } \\
\hline Distance(m) & 0.35 & 0.45 & 0.55 & 0.65 & 0.75 \\
$P_{R x}(\mathrm{dBm})$ & -10.28 & -12.88 & -13.21 & -15.03 & -16.19 \\
Actuation & Yes & Yes & Yes & No & No \\
\hline \multicolumn{7}{c}{ Signal generator power: 10 dBm } \\
\hline Distance(m) & 0.15 & 0.20 & 0.25 & 0.30 & 0.35 \\
$P_{R x}(\mathrm{dBm})$ & -9.15 & -11.09 & -12.67 & -14.01 & -15.17 \\
Actuation & Yes & Yes & Yes & No & No \\
\hline \multicolumn{7}{c}{ Signal generator power: $5 \mathrm{dBm}$} \\
\hline Distance(m) & 0.05 & 0.10 & 0.15 & 0.20 & 0.25 \\
$P_{R x}(\mathrm{dBm})$ & -8.13 & -11.65 & -14.15 & -16.09 & -17.67 \\
Actuation & Yes & Yes & No & No & No \\
\hline \multicolumn{7}{c}{ Signal generator power: 0 dBm } \\
\hline Distance(m) & 0.05 & 0.10 & 0.15 & 0.20 & 0.25 \\
$P_{R x}(\mathrm{dBm})$ & -13.13 & -16.65 & -19.15 & -21.09 & -22.67 \\
Actuation & Yes & No & No & No & No \\
\hline \hline
\end{tabular}

minimum $V_{C C} / 2=0.45 \mathrm{~V}$ that was mentioned in Section $\mathrm{V}$. When $\mathrm{V}_{\mathrm{EN}}$ dropped below the threshold, the output voltage of the charge pump IC was disabled and the $\mathrm{p}$-i-n diodes returned to the "OFF" state within approximately $100 \mathrm{~ms}$.

A series of time-domain measurements were taken in order to verify the previously described response using the oscilloscope model: LeCroy wavepro 7300A. Fig 17(a) shows the rectifier output voltage in the presence (RF signal ON) of a strong enough interfering $1.6 \mathrm{GHz}$ signal and in its absence (RF signal OFF) when a metallic screen blocks the interferer, for three different input power levels $\left(P_{R x}>-13 \mathrm{dBm}\right)$. When the received power is high enough the output of the rectifier $\left(V_{\text {Rect }}\right)$ is higher than $0.43 \mathrm{~V}$ and the output of the booster $\left(V_{\text {Booster }}\right)$ rises to $1.8 \mathrm{~V}$, high enough to actuate the $\mathrm{p}-\mathrm{i}-\mathrm{n}$ diodes and cause the dual-band response. When the RF signal is blocked $V_{\text {Rect }}$ goes to zero and $V_{\text {Booster }}$ drops below the $0.9 \mathrm{~V}$ which is the minimum diode actuation voltage depicted in Fig. 18. As a result the diodes remain unbiased and the filter response remains singleband. Fig 17(b) shows that when $P_{R x}$ power is below $-13 \mathrm{dBm}$ the variations in the rectifier output voltage $\left(V_{\text {Rect }}\right)$ do not have any effect on $V_{\text {Booster, }}$ since they are below the minimum required $0.43 \mathrm{~V}$ threshold. In order to demonstrate the dynamic response of the filter according to the power level of the external interferer in a continuous, real-time manner the rectified voltage $V_{\text {Rect }}$ and $V_{\text {Booster }}$ were recorded when the distance between the transmitter and the rectenna was continuously varied. The results are presented in Fig. 18. When $V_{\text {Rect }}$ (blue line) rises above the $0.43 \mathrm{~V}$ threshold $V_{\text {Booster }}$ (red line) rises instantly to $1.8 \mathrm{~V}$ and biases the diodes making the filter dual-band. However, when the distance is big enough to drop the rectified voltage $V_{\text {Rect }}$ below $0.43 \mathrm{~V}$, $V_{\text {Booster }}$ drops below the diode actuation voltage $(0.9 \mathrm{~V})$ and the filter becomes single-band.

In order to verify the successful implementation and the performance of the DUT, S-parameter measurements (Fig. 6 and 7) of the dual-layer filter shown in Fig. 14 were taken in 
both the absence and presence of the RF triggering signal. The setup is presented in Fig. 15(b). Test resistor in Fig. 14(b) was disconnected before the final measurements. RF signals at multiple power levels were generated by the signal generator and were used to wirelessly and dynamically actuate the p-i-n diodes and reconfigure the BPF from different distances between the transmitter and the receiver antennas. The measurement results of the DUT are summarized in Table III. It can be seen that in all cases, a received power greater than approximately $-13 \mathrm{dBm}$ successfully actuates the p-i-n diodes, and thus achieves the desired reconfiguration of the SIR filter from a single-band to a dual-band response. It is worth mentioning that for a power level below $-13 \mathrm{dBm}$, the primary design principle for the RF triggered PMU combined module will change drastically. First, the rectifier design needs to exploit the full potential of unconventional methods to realize higher DC conversation efficiency. Secondly, as mentioned before, the PMU is optimized for peak performance with the physically achievable rectifier's efficiency presented in section IV. An alternative approach could be a fully passive PMU with ultra-low power dc-to-dc passive converter based on voltagestepping up transformer, field effect transistor (FET) and an oscillator [46]. In addition, it has to be pointed out that the variation of $V_{\text {Rect }}$ (as long as $V_{\text {Rect }}>0.43 \mathrm{~V}$ ) does not affect the filter's dual-band response which remains the same as the one shown in Fig 6 The only thing that effectively affects the filter response is whether $V_{\text {Rect }}$ is higher or lower than the $0.43 \mathrm{~V}$ threshold.

\section{CONCLUSION}

A dynamically reconfigurable single- to dual-band BPF operating at $2.45 \mathrm{GHz}$ for WiFi applications or at $2.45 \mathrm{GHz}$ and $1.6 \mathrm{GHz}$ (GPS applications) has been introduced. The proposed filter consists of coupled-line sections with p-i-n diodes at their ends. The p-i-n diode switches can electrically connect or disconnect the coupled-line sections and therefore switch between single-band and dual-band responses. The diode biasing can happen dynamically in the presence of a low power $(-13 \mathrm{dBm}) 1.6 \mathrm{GHz}$ RF signal. The RF signal is collected by an RF triggered PMU that consists of a low profile compact-size PIFA antenna, a voltage doubler rectifier with $47 \%$ efficiency at $-13 \mathrm{dBm}$ and a dc output voltage of $0.43 \mathrm{~V}$ across a $5.1 \mathrm{~K} \Omega$ load, and a dc-to-dc power booster.

With the diodes in the "OFF" state the filter operates as a single-band BPF. When an RF signal at $1.6 \mathrm{GHz}$ is received from the rectenna, its rectified output is used as the enabling voltage $\left(V_{E N}\right)$ for the charge pump IC, and then the active dc-todc power booster supplies the filter's four p-i-n diodes with sufficient dc power to turn them to the "ON" state. With the four diodes in the "ON" state the filter operates as a dual-band filter. When the wirelessly received RF signal at $1.6 \mathrm{GHz}$ is suppressed, the filter becomes a single-band filter BPF again. Consequently, the dynamically reconfigurable filter allows the $1.6 \mathrm{GHz}$ passband only when a wireless $1.6 \mathrm{GHz}$ signal is received.

The current work indicates that a simple RF harvesting system can be designed for dynamic RF triggering of reconfigurable microwave devices and for the proof-of-concept a single- to dual-band filter has been successfully implemented and tested. The filter operates as a single-band BPF with low insertion loss $(0.84 \mathrm{~dB})$ and $15 \%$ fractional bandwidth, at 2.45 $\mathrm{GHz}$ intended for WiFi applications while in the presence of a wireless signal as low as $-13 \mathrm{dBm}$ it converts into a dual-band BPF. For the additional dynamically formed passband around 1.6 $\mathrm{GHz}$ the insertion loss is $1.2 \mathrm{~dB}$ and the fractional bandwidth is $12.7 \%$. In both single- and dual-band operation states the BPF shows a wide stopband $\left(>3 \times f_{o}\right)$ at the high frequency band with high $\left|S_{21}\right|$ suppression $(<-20 \mathrm{~dB})$. The lower passband can be used for GPS signals after the extremely low power GPS signals $(-115 \mathrm{dBm})$ are adequately amplified at the receiver. Consequently, a dynamically reconfigurable SIR filter for WLAN and GPS applications has been successfully implemented, and has been presented for the first time to the best of our knowledge.

\section{REFERENCES}

[1] B. Lui, F. Wei, and X. Shi, "Switchable bandpass filter with two-state frequency responses," Electron. Lett., vol. 47, no. 1, pp. 40-41, Jan. 2011.

[2] P. W. Wong and I. C. Hunter, "Electronically reconfigurable microwave bandpass filter," IEEE Trans. Microw. Theory Techn., vol. 57, no. 12, pp. 3070-3079, Dec. 2009.

[3] G.-L. Dai, Y.-X. Guo, and M.-Y. Xia, "Dual-band bandpass filter using parallel short-ended feed scheme," IEEE Microw. Wireless Compon. Lett., vol. 20, no. 6, pp. 325-327, Apr. 2010.

[4] X. Y. Zhang and Q. Xue, "Novel dual-mode dual-band filters using coplanar-waveguide-fed ring resonators," IEEE Trans. Microw. Theory Techn., vol. 55, no. 10, pp. 2183-2190, Oct. 2007.

[5] G. Dai and M. Xia, "Design of compact dual-band switchable bandpass filter," Electron. Lett., vol. 45, no. 10, pp. 506-507, May. 2009.

[6] J. Shi and Q. Xue, "Novel balanced dual-band bandpass filter using coupled stepped-impedance resonators," IEEE Microw. Wireless Compon. Lett., vol. 20, no. 1, pp. 19-21, Dec. 2009.

[7] C.-H. Tseng and H.-Y. Shao, "A new dual-band microstrip bandpass filter using net-type resonators," IEEE Microw. Wireless Compon. Lett., vol. 20, no. 4, pp. 196-198, Mar. 2010.

[8] J.-T. Kuo and H.-P. Lin, "Dual-band bandpass filter with improved performance in extended upper rejection band," IEEE Trans. Microw. Theory Techn., vol. 57, no. 4, pp. 824-829, Mar. 2009.

[9] S.-F. Chao, C.-H. Wu, Z.-M. Tsai, H. Wang, and C. H. Chen, "Electronically switchable bandpass filters using loaded steppedimpedance resonators," IEEE Trans. Microw. Theory Techn., vol. 54, no. 12, pp. 4193-4201, Dec. 2006.

[10] M. A. B. Abbasi, M. A. Antoniades, and S. Nikolaou, "A Compact Reconfigurable NRI-TL Metamaterial Phase Shifter for Antenna Applications," IEEE Trans. Antennas Propag., vol. 66, no. 2, pp. 10251030, Nov. 2017.

[11] S. Arain, P. Vryonides, M. A. B. Abbasi, A. Quddious, M. A. Antoniades, and S. Nikolaou, "Reconfigurable Bandwidth Bandpass Filter With Enhanced Out-of-Band Rejection Using $\pi$-Section-Loaded Ring Resonator," IEEE Microw. Wireless Compon. Lett., vol. 28, no. 1, pp. 28-30, Jan. 2018.

[12] S. D. Assimonis and A. Bletsas, "Energy harvesting with a low-cost and high efficiency rectenna for low-power input," in 2014 IEEE Radio and Wireless Symp. (RWS), Newport Beach, CA, 2014, pp. 229-231.

[13] S. D. Assimonis, S. N. Daskalakis, and A. Bletsas, "Efficient RF harvesting for low-power input with low-cost lossy substrate rectenna grid," in 2014 IEEE RFID Technology and Applications Conf. (RFIDTA), Tampere, 2014, pp. 1-6.

[14] A. Collado and A. Georgiadis, "Conformal Hybrid Solar and Electromagnetic (EM) Energy Harvesting Rectenna," IEEE Trans. Circuits Syst. I: Regular Papers, vol. 60, no. 8, pp. 2225-2234, Jan. 2013.

[15] A. Georgiadis, G. V. Andia, and A. Collado, "Rectenna design and optimization using reciprocity theory and harmonic balance analysis for electromagnetic (EM) energy harvesting," IEEE Antennas Wireless Propag. Lett., vol. 9, pp. 444-446, May. 2010. 
[16] C. Mikeka, H. Arai, A. Georgiadis, and A. Collado, "DTV band micropower RF energy-harvesting circuit architecture and performance analysis," in 2011 IEEE International Conference on RFIDTechnologies and Applications, Sitges, 2011, pp. 561-567.

[17] M. Piñuela, P. D. Mitcheson, and S. Lucyszyn, "Ambient RF Energy Harvesting in Urban and Semi-Urban Environments," IEEE Trans. Microw. Theory Techn., vol. 61, no. 7, pp. 2715-2726, May. 2013.

[18] J. Zbitou, M. Latrach, and S. Toutain, "Hybrid rectenna and monolithic integrated zero-bias microwave rectifier," IEEE Trans. Microw. Theory Techn., vol. 54, no. 1, pp. 147-152, Jan. 2006.

[19] J. A. Hagerty, F. B. Helmbrecht, W. H. McCalpin, R. Zane, and Z. B. Popovic, "Recycling ambient microwave energy with broad-band rectenna arrays," IEEE Trans. Microw. Theory Techn., vol. 52, no. 3, pp. 1014-1024, Mar. 2004.

[20] J. A. G. Akkermans, M. C. v. Beurden, G. J. N. Doodeman, and H. J. Visser, "Analytical models for low-power rectenna design," IEEE Antennas Wireless Propag. Lett., vol. 4, pp. 187-190, Jun. 2005.

[21] E. Falkenstein, M. Roberg, and Z. Popovic, "Low-Power Wireless Power Delivery," IEEE Trans. Microw. Theory Techn., vol. 60, no. 7, pp. 2277-2286, May. 2012.

[22] P. Ji-Yong, H. Sang-Min, and T. Itoh, "A rectenna design with harmonic-rejecting circular-sector antenna," IEEE Antennas Wireless Propag. Lett., vol. 3, no. 1, pp. 52-54, Jan. 2005.

[23] A. Dolgov, R. Zane, and Z. Popovic, "Power management system for online low power RF energy harvesting optimization," IEEE Trans. Circuits Syst. I: Regular Papers, vol. 57, no. 7, pp. 1802-1811, Jan. Jan. 2010.

[24] A. Costanzo, A. Romani, D. Masotti, N. Arbizzani, and V. Rizzoli, "RF/baseband co-design of switching receivers for multiband microwave energy harvesting," Sens. Actuator A-Phys., vol. 179, pp. 158-168, Jun. 2012.

[25] D. Masotti, A. Costanzo, P. Francia, M. Filippi, and A. Romani, "A loadmodulated rectifier for RF micropower harvesting with start-up strategies," IEEE Trans. Microw. Theory Techn., vol. 62, no. 4, pp. 9941004, Apr. 2014.

[26] R. Zhang and L. Zhu, "Design of a compact dual-band bandpass filter using coupled stepped-impedance resonators," IEEE Microw. Wireless Compon. Lett., vol. 24, no. 3, pp. 155-157, Jan. 2014.

[27] Z. Zhang, Y.-C. Jiao, X.-M. Wang, and S.-F. Cao, "Design of a compact dual-band bandpass filter using opposite hook-shaped resonator," IEEE Microw. Wireless Compon. Lett., vol. 21, no. 7, pp. 359-361, Jul. 2011.

[28] R. Zhang and L. Zhu, "Synthesis and design of wideband dual-band bandpass filters with controllable in-band ripple factor and dual-band isolation," IEEE Trans. Microw. Theory Techn., vol. 61, no. 5, pp. 18201828, May. 2013.

[29] H. Zhu and A. M. Abbosh, "Single-and Dual-Band Bandpass Filters Using Coupled Stepped-Impedance Resonators With Embedded Coupled-Lines," IEEE Microw. Wireless Compon. Lett., vol. 26, no. 9, pp. 675-677, Aug. 2016.

[30] Radio-Electronics.com. (September). WiFi Channels, Frequencies Bands and Bandwidths. [online] Available: https://www.radioelectronics.com/info/wireless/wi-fi/80211-channels-numberfrequencies-bandwidth.php Accessed on: Sep. 2018.

[31] R. C. Hansen and R. E. Collin, "Electrically small antennas: canonical types" in Small antenna handbook, Wiley-IEEE Press, 2011, pp. 93-113.

[32] K.-L. Wong, "Compact broadband microstrip antennas" in Compact and broadband microstrip antennas. John Wiley \& Sons, 2004, pp. 45-79.

[33] J. C. Salmon, "Circuit topologies for single-phase voltage-doubler boost rectifiers," IEEE Trans. Power Electron., vol. 8, no. 4, pp. 521-529, Oct. 1993.

[34] M. E. N. America. (2017). Ceramic Capacitor Kit [online] Available: https://www.digikey.co.uk/product-detail/en/murata-electronics-northamerica/GJM03-KIT-TTOL-DE/490-12155-ND/5414396, Accessed on: Feb. 2016.

[35] S. D. Assimonis, S. N. Daskalakis, and A. Bletsas, "Sensitive and Efficient RF Harvesting Supply for Batteryless Backscatter Sensor Networks," IEEE Trans. Microw. Theory Techn., vol. 64, no. 4, pp. 1327-1338, Mar. 2016.

[36] H. Sun, Y. x. Guo, M. He, and Z. Zhong, "Design of a High-Efficiency 2.45-GHz Rectenna for Low-Input-Power Energy Harvesting," IEEE Antennas Wireless Propag. Lett., vol. 11, pp. 929-932, Aug. 2012.

[37] T. Instruments. (February). Texas Instruments Charge Pump IC: TPS60301. [online] Available: http://www.ti.com/product/TPS60301, Accessed on: Feb. 2016.
[38] A. Boaventura, A. Collado, N. B. Carvalho and A. Georgiadis, "Optimum behavior: Wireless power transmission system design through behavioral models and efficient synthesis techniques," IEEE Microw. Mag., vol. 14, no. 2, pp. 26-35, Mar. 2013.

[39] A. Costanzo, M. Fabiani, A. Romani, D. Masotti and V. Rizzoli, "Codesign of ultra-low power RF/Microwave receivers and converters for RFID and energy harvesting applications," in Proc. IEEE MTT-S IMS, Anaheim, CA, May 2010, pp. 856-859.

[40] B. Kevin, "Radiating and balanced mode analysis of PIFA shorting pins," in Proc. IEEE ISAP, San Antonio, TX, USA, vol.4, Jun. 2002, pp. 508-511.

[41] T. Taga and K. Tsunekawa, "Performance Analysis of a Built-In Planar Inverted-F Antenna for $800 \mathrm{MHz}$ Band Portable Radio Units," IEEE J. Sel. Areas Commun., vol. 5, no. 5, pp. 921-929, Jun. 1987.

[42] F. C. Commission. (September). FCC Rules ATC 25.253. [online] Available: https:/www.gpo.gov/fdsys/pkg/CFR-2010-title47vol2/pdf/CFR-2010-title47-vol2-sec25-253.pdf Accessed on: Sep. 2018.

[43] S. Solutions. (February). PIN Diodes Available: http://www.skyworksinc.com/Product/251/DSM8100-000 Accessed on: Feb. 2016.

[44] Coilcraft. (February). Fixed Inductors 0402CS [online]. Available: https://eu.mouser.com/datasheet/2/597/0402cs-253326.pdf, Accessed on: Feb. 2016.

[45] S. Solutions. (February). Schottkey diode [online]. Available: http://www.skyworksinc.com/Product/511/SMS7630_Series, Accessed on: Feb. 2016.

[46] S. Adami, V. Marian, N. Degrenne, C. Vollaire, B. Allard and F. Costa, "Self-powered ultra-low power DC-DC converter for RF energy harvesting," in Proc. IEEE Faible Tension Faible Consommation, Paris, pp. 1-4, Jun. 2012. 